\section{Spirituality and religion in pain and pain management}

\author{
Ozden Dedeli,1 Gulten Kaptan² \\ 1Department of Internal Medicine, Celal \\ Bayar University School of Health, \\ Manisa; 2EIderly Care Programme, \\ Uskudar University Vocational School \\ of Health Services, Istanbul, Turkey
}

\begin{abstract}
Pain relief is a management problem for many patients, their families, and the medical professionals caring for them. Although everyone experiences pain to some degree, responses to it vary from one person to another. Recognizing and specifying someone else's pain is clinically a well know challenge. Research on the biology and neurobiology of pain has given us a relationship between spirituality and pain. There is growing recognition that persistent pain is a complex and multidimensional experience stemming from the interrelations among biological, psychological, social, and spiritual factors. Patients with pain use a number of cognitive and behavioral strategies to cope with their pain, including religious/spiritual factors, such as prayers, and seeking spiritual support to manage their pain. This article provides an overview of the complex phenomenon of pain, with a focus on spiritual and religious issues in pain management.
\end{abstract}

\section{Background}

Studies concerning pain can be traced back as early as Babylonian clay tablets. Aristotle (4th century B.C.) described pain as emotion, being the opposite of pleasure. Emotions certainly play an important role in pain perception, but we know that there is much more involved in this process.

In the middle Ages, pain was considered a religious matter. Pain was seen as God's punisment for sins, or as evidence that an individual was possessed by demons. This definition of pain is stil embraced by some patients who might tell the health professionals that the suffering is their cross to bear. Pain relief may not be appealing to those individuals who believe in this definition of pain. Spiritual counseling thus may be more of a priority than medical management. ${ }^{1}$ Many Hindu believers envision pain as a divinely or dained punishment, or resulting from personal actions. In Islam, it can be punitive or Allah's will. A popular
Buddhist belief is that suffering is the cost of attachment.2

The 1960s brought a wave of interest in spirituality and consciousness researches and changes in attitudes and beliefs toward medicine. Postmodern thought fostered acceptance of diverse medical systems and client empowerment. More than 150 years later, medicine began the return to the mind/body/spirit perception of health and care. Mind-body-spiritual therapies include behavioral (meditation, biofeedback, hypnosis e.g.), social and spiritual (prayer and mental healing) approaches. ${ }^{2}$

\section{Spirituality and religion}

Spiritual and religious beliefs are important in many individuals' lives. However, religious and spirituality are not the same. These beliefs can influence lifestyle, attitudes, and feelings about life, pain, and death. Some organized religions specify practice about diet, birth control, illness, and medical care. Spiritual beliefs often place a greater significance at the time of illness than any other time in a person's life. Both religious and spiritual beliefs help some people accept their own illness and help explain illness for others. Spiritual beliefs often help people plan for the future. Also, religion can both help people live more profound lives as well as strengthen or console people during suffering and in preparation for inevitable death. By providing meaning to life and death, religion can supply the client, the family, and health professionals with a sense of strength, security, and faith during a time of need. 1,3

Spirituality is often defined as the experience of transcendence, connectedness, meaning, and purpose in life, integrating aspects of the self or a search for the sacret. These definitions reflect a construction of spirituality that is individualistic and not necessarily associated with traditional religion. Such secularization of spirituality reflects a growing tendency in Western socities to retain some aspects of religiosity, such as transcendence, while rejecting the institutional and doctrinal aspects of organized religion. ${ }^{4,5}$ Religion traditionally connoted a set of beliefs and practises around the existense of something sacred or divine such as God, a higher power, or an ultimate truth. ${ }^{4}$ According to a literature review about the meaning of spirituality one of major hindrances in defining spirituality is its relationship with religion. Also, spiritual well being is neither synonymous, or with religiosity. Religion is a social instution in which a group of people participate rather than an individual search for meaning. As such religion is more about systems of practises and beliefs within which a social group engage. This isn't
Correspondence: Ozden Dedeli, Celal Bayar University Shool of Health Istasyon Mevkii 45020 Manisa, Turkey.

Tel. +90.236.231.8373-5820 - Fax: +90.236.232.0058

E-mail:ozdendedeli@yahoo.co.uk

Key words: pain management, spirituality, religion.

Contributions: the authors contributed equally.

Conflict of interests: the authors report no conflict of interests.

Received for publication: 9 March 2013

Accepted for publication: 2 June 2013.

This work is licensed under a Creative Commons Attribution NonCommercial 3.0 License (CC BYNC 3.0).

(C) Copyright O. Dedeli and G. Kaptan, 2013 Licensee PAGEPress, Italy

Health Psychology Research 2013; 1:e29

doi:10.4082/hpr.2013.e29

to say that religion has no part to play in spirituality for some people. A researcher suggests that religion can provide a platform for the expression of spirutailty. However she also proposes that religious beliefs and practises can be dispiriting for a person, inhibiting their own individual spirutailty, whereby religious belief systems can have negative effects on the on the health of an individuals beliefs and expectations. ${ }^{6}$

\section{Spirituality, religion and pain}

Pain is a complex phenomenon involving a cascade of behavioral responses, thoughts, and emotions. Many nonphysiologic factor (psychological, familial and societal attitudes, life stressors, and cultural or spritual) contributing to the experience of and response to pain. Emotional stress such as anxiety and depression play a key role in experience of pain. In recently studies shown that people living with chronic pain may report more intense pain and related disability, if they have depression, anxiety, or both. In addition, the fear of pain may be caused more disability than the pain itself. In another study found that there is a cyclical pattern of chronic pain leading to depression and depression causing a increase in chronic pain, creating a mutually reinforcing relationship. ${ }^{7-9}$ Also, family and caregivers' beliefs and attitudes towards pain, either positively and negatively to tolerate and express pain are important. Health professionals who provide care to patients with chronic pain are the most important agents for pain management. 
Therefore, health professionals should be attuned to the biological, psychosocial needs of their patients in their efforts to holistically address pain. ${ }^{10,11}$

Pain management may entail various behavioral, religious, medication (prescription and alternative), and surgical options. One of the medical care goals is to explore the psychosocial factors involved in the pain experience and attempt to address misconceptions, modify or change unhelpful coping strategies and enforce positive ones. Since pain experienced in the context of biopsychosocial-spiritual system, it is should be understood that, individuals' capacities to cope, tolerate, and accept disease and pain entail multiple levels of experience an thought. Therefore, many researchers suggested the biopsychosocial model (BPSM), as a framework for understanding the effect of individuals' biological, psychological, and social experiences on disease. More recently, spirituality as a concept has been included into the BPSM. As the biopsychosocial- spiritual model (BPSSM) suggests illness disrupts the biological, interpersonal, and spiritual relationships unique to the individual. The BPSSM recognizes the potential impact of spiritual and religious variables that may increase or decrease experience of illness and pain responsiveness. 12 Similarly, researches have been shown that negative spiritually based cognitions (e.g. God is abandoning me) is related to increased pain sensitivity. 13 The BPSSM suggests individuals' spirituality and spiritual forms may play an important role in coping with illness and pain. ${ }^{12}$

Spirituality and religion may influence the experience of pain and fatigue. Religious people are less likely to have pain and fatigue according to Baetz and Bowen. They obtained data from 37.000 individuals, 15 years of age or older, with fibromyalgia, back pain, migraine headaches and chronic fatigue syndrome, and those who are spiritual but not affiliated with regular worship attendance are more likely to have those conditions. They also found that those with chronic pain and fatigue were more likely to use prayer and seek spiritual support as a coping method compared to other people. Pain sufferers who were both religious and spiritual were more likely to have beter psychological well being and use positive strategies. Therefore, it would seem appropriate for an individuals' spirituality and/or religion to be considered as part of the evaluation and management plan, as it may be a useful coping strategy. ${ }^{14}$

Spiritual interventions vary according to the culture. Pray is a universal spiritual practice; it may take the form of intercessory prayer, confession, gratitude, or silent communion. Prayer involves no direct physical contact and no attempt to do anything or give anything. The only goal is to become a loved one for his or her God. Seeking medical care and using prayer are not mutually exclusive activities. ${ }^{15}$ Pain is often referenced in the context of people's relationships with God. God is responsible for health, and spiritual beliefs are most effective way to influence healing. Patients with pain may practice a number of religious and spiritual interventions, such as prayer, seeking spiritual support, to cope with their pain. ${ }^{16}$ Research has found that the majority of patients with chronic pain use religious and/or spiritual forms such as prayer and spiritual support for coping with their pain. This has been characterized as either external powerful sources of disease control and on internal powers and virtues. Intrinsic religion and reapprasial were valued moderately, while spiritual quest orientation was of minor relevance. The internal sources of disease controls such as conscious and healthy living and positive attitudes were the strongest predictors of patients's reliance on spirituality and religion apart from the religious denomination. ${ }^{17}$

Correlational research has suggested that individuals with strong religious and spiritual lives tend to be healthier, psychologically and physically. In a meta-analysis of 147 independent studies of religiousness and depressive symptoms, religiousness appeared to protect aganist depression, particularly in times of major life stress. This relationship also held true in a study of chronic pain patients; those who reported more spiritual experiences also reported more positive mental health. Furthermore, the relationship between spirituality and mental health was strongest among those reporting higher levels of pain. ${ }^{18}$

Whitford et al. ${ }^{19}$ questioned 449 Australians with pain and fatigue symptoms and found that the low faith group appeared to enjoy their life more than the high faith group. Beliefs about the nature of God run the gamut between a loving and a punishing God. Future research should include not only the presence or absence of a belief in a higher power, but also the type of beliefs the participant holds about God, since the valence of belief can affect mental and physical health outcomes. ${ }^{19}$ In the study by Newberg et al. ${ }^{20}$ negative beliefs and attitudes stimulate intense activity in the limbic system resulting in a flood of chemicals that often trigger feelings of fear, anger, and feelings of disconnection. Negative meaning making appears to diminish resilience leading to poorer coping abilities. The valence of spiritual and religious coping is critical to meaning making and a patients' ability to cope with chronic pain. ${ }^{20}$ While prayer is often considered a positive coping strategy, the content and valence of prayer can impact outcomes. Prayer, when used as a means to relinquish control and responsibility for pain solutions, can negatively impact disability and perceived self control.21,22
0'Connell-Edwards et al.23 found that the highest levels of psychopathology and affective reactions to pain were found in the highest frequency of church attendees and that moderate church attendees experienced a lower intensity of pain and psychopathology. It may be that the moderate use of religion and spirituality resources are a more effective tool for treating pain when the individual stil retains some form of self efficacy and responsibility, but also feels supported by their higher power. Balance is needed between self efficacy and the relinquishment of control to an outside party, whether that outside force is religious and spiritual or medical and pharmacological. The best treatment outcomes may be experienced when an individual's meaning making system includes responsibility for some sort of self efficacy in the treatment process. When people cannot find relief from the medical profession for intense and debilitating pain they are likely to turn to an alternative source for help in coping. ${ }^{24-26}$

Bussing et al. used the Spiritual and Religious Attitudes in Dealing with Illness (SpREUK) questionnaire and the Adaptive Coping with Disease (AKU) questionnaire to discover if spirituality and religiosity are a relevant resource for 580 patients coping with chronic pain conditions. Fifty-eight per cent of patients were grounded on religion or spirituality and give meaning but not in the context of religion or spirituality. Fifty percent of them claimed that they were not religious, $32 \%$ of them religious but not spiritual, $8 \%$ of them spiritual but not religious and $18 \%$ of them both religious and spiritual. Stepwise regression analysis revealed that the internal sources of disease control such as Conscious and Healthy Way of Living and Positive Attitudes were the strongest predictors of a patient's reliance on spirituality and religiosity. Non-religious and non-spiritual patients had significantly lower internal or behavioral coping styles, which may be related to a more closed minded attitude toward possibilities, less meaning and/or purpose seeking behavior, lower self efficacy, and a more negative approach towards life's challenges. ${ }^{27}$

Open mindedness may also be a predictor of well being. In the study by Dezutter et al. sent questionnaires to 155 chronic pain patients and to 166 health participants without pain to compare their relationship between religious attitudes and subjective well-being by using a Literal Inclusion-Exclusion scale and a Symbolic Inclusion-Exclusion scale. ${ }^{28}$ Literal Inclusion individuals define religious contents in a closed minded dogmatic fashion and Literal Exclusion individuals reject the possibility of religious reality. Symbolic inclusion individuals are more open minded and assume that several interpretations of religious content is possible, and Symbolic Exclusion indi- 
viduals are less judgmental toward religiosity but do not think they need religiosity to find meaning for their life. Higher levels of wellbeing in the chronic pain sample were significantly related to Symbolic Inclusion and Symbolic Exclusion and lower levels of wellbeing were significantly related to Literal Exclusion, suggesting that a more open minded attitude toward religion and what lies beyond the ordinary might buffer the effects of chronic pain by offering meaning making, purpose, and hope.

Pain and disease can challenge one's belief system, although individuals experiencing chronic pain are more likely to become religious and spiritual after the onset of their condition. Chronic pain may cause people to turn to the practices that religious and spiritual institutions advocate for better psychological, mental, and even physical health. ${ }^{29-32}$

\section{Spiritual interventions based on pain management}

Spirituality-based strategies are commonly used to cope with chronic pain. Chronic pain patients with a variety of conditions (e.g. musculoskeletal pain, cancer, or sickle cell) usually report that religiousness and spirituality are important in their live.33 Many chronic pain patients use religious and/or spiritual forms of coping such as prayer and spiritual support to cope with their pain. ${ }^{34}$ There appears to be a positive association between religiousness and spirituality resuling in appears to be a positive association between religiousness and spirituality resulting in improved well-being and negative association with depressive and anxiety symtoms. ${ }^{33}$ Another study suggests the use of prayer as a coping method in hard times. Among 122 patients with chronic musculoskeletal pain ( $55 \%$ back pain), private religious practice (e.g. prayer, reading religious materials) were inversely correlated with good physical health. ${ }^{35}$ In 2001, Keefe et al. ${ }^{36}$ evaluated the role of daily spiritual experiences and daily religious/spiritual coping with pain in the experience of individuals dealing with rheumatoid arthritis. These participants reported using positive religious and spiritual coping strategies much more frequently than negative religious and spiritual coping strategies. This finding lend support to the possibility that coping with chronically painful medical condition may sensitize one or even enhance spiritual or religious connectedness. Whether positive or negative, religious and spiritual coping strategies thus seem to influence suffering from experienced pain. This research identified that positive religious and/or spiritual interventions appears to play an important role in pain management and reduction of suf-

\section{fering. 37,38}

Some researchers have found that some types of religious and/or spiritual coping are adaptive (i.e., positive religious coping) while other types are maladaptive (i.e., negative religious coping). Positive coping includes collaborative problem solving with God, helping others indeed, and seeking spiritual support from the community and from a higher power. Negative coping includes deferring all responsibility to God, feeling abandoned by God, and blaming God for difficulies. ${ }^{39,40}$ A study by Bush et al. examining the use of positive coping (looks to a higher power for strength, comfort, and support) and negative coping (divine discipline, divine chastisement, God's punishment) found that positive coping was associated with adaptive outcomes (e.g., better mental or physical health). Negative coping appeared to be more adaptive and those who felt they were punished by God saw the pain as retribution from God, and the other negative copiers made patients feel abandoned by God during the time when they most needed support. 41

Many religious and spiritual practices are intended to help the practitioner to experience feelings of spiritual support. A study by Wiech et al. used Functional Magnetic Resonance Imaging (fMRI) to study the key areas in the brain for modulating pain intensity. Twelve practicing Catholics and twelve non-religious, non-spiritual individuals participated. They were shown two pictures of women in a similar pose, the Virgin Mary and an unknown woman, while they received a repetitive noxious electrical stimulation. Both groups were equally sensitive to the pain but the religious group reported less pain when looking at the picture of the Virgin Mary while the non-religious group reported the same amount of pain. The non-religious group preferred the picture of the other woman although the picture did not lessen their pain. The Catholic participants reported that they were in a calm, meditative state when the religious image was presented to them. These researchers found that the right ventrolateral prefrontal cortex (VLPFC) cluster in the brain was specifically activated in the religious sample when looking at the Virgin Mary, but not in the nonreligious sample. The VLPFC is also involved in other cognitive processes which is long-term memory and working memory maintenance. Post scan reports suggested that the Catholic sample used a strategy known as self-focused reappraisal that allowed them to down regulate the perceived intensity of the pain when presented with a religious image. The image of the Virgin Maryis felt to Catholics projects a calming presence of understanding and support that allows these individuals to feel supported by their higher power. Meaning making symbols can thus influence the experience of pain. 42
Bush et al. also described whether religious and non-religious coping strategies relate to outcomes after controlling for the influence of demographic variables. This study also evaluated whether different forms of religious coping were associated with different outcomes. The researchres gathered information from 61 patients seeking treatment at a pain management center. Most of patient were Caucasian women with fibromyalgia, arthritis, post surgical, and carpal tunel pain. Patients provided a wide array of demographic data, 51 percent indicated that they were moderately religious and 30 percent reported that they were very religious. The participants also completed questionnaires concerning how pain, affected their lives, how they coped with the pain, the role and functional of religious faith and practice in their lives, their general mood, and outcomes related to their coping process. As regards the first question, religious and nonreligious coping were moderately related to pain outcomes after accounting for the influence of demographic variables. More specifically, the positive religious coping items were correlated with increased positive affects and a strengthening of religious faith and practice. Religious coping efforts were more helpful than nonreligious coping. ${ }^{41}$

Giving attention to these religious processes may improve treatment outcomes.42 Dunn and Horges studied the frequency and type of religious and nonreligious coping strategies used by elderly individuals to manage chronic pain, and ascertained if there were differences in the use of religious and nonreligious coping across gender and race. Researchers suggested that elderly individuals report using a repertoire of pharmacologic and nonpharmacologic strategies to manage chronic pain. Older women and elderly individuals of minority racial background reported using religious coping strategies to manage their pain more often than did older Caucasian men. Older women also reported using diversion and exercise significantly more often than did older men. 43

A study by Wachholtz and Pargament (2005) randomly assigned 84 college students to one of three groups, relaxation, secular meditation, and spiritual meditation. Participants filled out psychological and spiritual assessments prior to learning their technique. After practicing their technique for 20 minutes a day for two weeks, each individual placed their hand up to their wrist in a cold water bath and held it there for as long as they could. Psychological and spiritual assessments were completed again. The spiritual meditation group reported significantly more mystical experiences than the other two groups and a greater increase in closeness to God. Furthermore, although they reported the same subjective level of pain as the other groups, 
they were able to endure the pain level almost twice as long as the other two groups. There is some debate regarding the role of spirituality and the impact of meditation on health. ${ }^{44}$ In addition, Wachholtz and Pargament reported their effect on 83 participants who met the criteria for vascular headache. The participants were randomly assigned into four groups, Spiritual Meditation, Internal Secular Meditation, External Secular Meditation, and Relaxation. They were assessed through a pretest on headache frequency and severity, affect, anxiety, depression, quality of life, self efficacy, religious demographics, spiritual well-being, and spiritual experiences. Following one month of 20 minutes a day practice, the participants returned to the lab to practice their technique followed by placing their hand in a cold pressor bath. Next they completed a follow-up assessment. The Spiritual Meditation group reported a significantly greater reduction in headaches and greater pain tolerance in comparison to the other groups as well as an increase in existential well-being. 45 The spiritual meditators in both studies focused on one of four phrases: God is peace, God is joy, God is good, or God is love. All four phrases express a sense of goodness, support and comfort similar to what the participants in the Wiech et al. study may have experienced when they viewed a picture of the Virgin Mary. Words and images that evoke the presence of love, support, and/or comfort thus appear to have a salutary effect on pain. Repeating these phrases, or using visual stimuli can make these spiritual resources more salient to individuals who are experiencing pain. 42

Spiritual coping is discussed in many studies, so far. Finally, both positive and negative spirituality and religious practices were strongly related to well-being for the clergy. In some of studies, reported cultural differences are affect the results that related to both negative and positive spiritual and religious coping. In these studies shown that, in different cultural settings are also affected spiritual and religious coping during times of stres and illness. 46

Muslims often believe illness and injury are caused by a higher power (Allah), they attribute their illness, injury, pain and sufferings to Allah thanking for good furtune of being allowed the special medical or/and surgical treatments. ${ }^{47}$ In Turkey, for instance, $90 \%$ of the population are Muslims. Also, there are some Jews, Christian, and others. Turkey is a unique country both as the majority of its's citizens are Muslim and also for their commitment to adapt a Western life style. In Turkish sources, little empirical research has explored the specific ways in which religious and spiritual coping may directly impact chronic pain. However, numerous studies demonstrated that there is a negative relationship between spiritually and symptoms related chronic disease (e.g. pain, fatigue, anxiety, depression, hopelessness). There is a positive relationship between spirituality and well-being, life satisfaction and the quality of life. Studies conducted in Turkey are given below. These studies are related to spirituality, pain and chronic illness.

A study by Ozer examined perception and definition of the quality of life in patients with heart failure. The research participants reported prayer is one of the most important things to improve the quality of life. 48 In another study, 336 individuals with chronic non-malignan pain have been assessed as to their pain distress and beliefs, attitudes towards pain. These participants reported, they pray for coping with a high level of pain distress, and pray that their pain should not start again. When their pain starts they squeeze their fists and clench their theeth in order to endure the severity of pain. 49

A study by Afsar and Pinar evaluated spirituality in cancer patients with various types of advanced cancer and found that spiritual activities influenced their general happiness and life satisfaction. Cancer patients also reported, when they experienced pain they preferred social isolation, a change in their enviroment, massage and lying down or resting as coping strategies. ${ }^{50} \mathrm{~A}$ another study by Babaoglu and $\mathrm{Oz}$ examined, psychological problems of spouses who take care of a terminal cancer patient. The spouse reported experiencing hopelessness, spiritual distress and failure in coping with social problems. 51

Karakavak and Cirak interviewed mothers with children having chronical diseases, about their feelings, adjustment, support systems during the care of their child. All mothers learned about their children's illness in hospitals. They felt shock, denial, uncertainty of their children's illness, and expressed resentment or/and rebelled aganist God. They were found to have used some strategies to cope with their children illness including religious belief, praying, receiving social support to their families and consulting to health professionals. ${ }^{2}$

In a study by Sulu mothers' spiritual coping strategies when their children are hospitalized in intensive care units were assessed. Mothers try to cope with the illness of their children by the help of spiritual feelings and live their spirituality through religious beliefs and practices (to pray, reciting the Koran, to perform namaze etc). Mothers attempted to perform religious practices (visiting shrines, having amulets, consulting to a hodja, to recite Koran, use herbal teas etc.), wanted to be near their children to touch to talk to them to kiss them to listen to their demands and to meet their needs in order to keep their morale high. These studies also found some adverse effects of religious and spiritual interventions as strategies to cope with chronic illnesses and their symptoms (pain, depression, anxiety, hopelessness, fatigue, distres). ${ }^{53}$

\section{Discussion}

Several spirituality interventions have been applied in nursing practice, such as prayer, use of honey. There are several spirituality interventions that should be researched and applied in holistic care. Spirituality interventions is very effective for individuals health, illness, and in recovering from diseases. Health professionals should try to discover and understand patients' way of life which have different beliefs, attitudes, styles, norms, habits, communication styles, etc. Regarding all these individual and social variations, health professional can choose the proper way to care for patients in the light of their belief systems and religious values. The most important role of the health professionals are to help their patients in the most appropriate and effective way. The health professionals should inquire about patients' cultural backgrounds and types of medication preffered in their religious and spiritual system. In addition, when assessing and treating patients with pain, health professionals may benefit from patients' descriptions of how they use spiritual and religious resources to cope with pain. Health professionals need to be more aware of the importance of spirituality and religion in helping and supporting people having pain. ${ }^{54-56}$

Once health professionals learn from patients about their spiritual or religious nature that might be crucial for their personal health care, they should, just as for any physical or psychosocial symptom, develop a pain treatment plan that reflects appropriate goals of care. As patients' needs drive the goals of care, it is important that both health professionals and their patients focus on those goals, especially when disagreements between the patient and health professionals are based on conflicts between spiritual and religious and medical needs. 57,58

Currently, studies suggest that few clinicians incorporate discussions about spirituality into their care of patients, while conversely many patients want spirituality to be considered within their health care options. Spiritual history should be taken as part of a holistic patient care. Health professionals need to be more aware of the importance of spirituality and religion in helping and supporting people in pain. ${ }^{17}$ 


\section{Conclusions}

In conclusion, this literature review highlights the importance of spirituality and religion as strategies for coping with pain. People with chronic pain turn to their religion and spirituality to cope with their condition. Religious or spiritual practices can help in managing pain in several ways. Although both religious and spiritual beliefs influence pain management, sometimes people believe that opioid substances or intravenous medication is forbidden in their religious belief and might reject medical or surgical pain interventions. Therefore, further research is needed to integrate spirituality and religion into clinical pain management.

\section{References}

1. White L, Duncan G. Medical surgical nursing: an integrated approach. 2nd Ed. New York: Delmar Thomson Learning; 2002.

2. Solimine MA. Spirituality. In: Hoeman SP, ed. Rehabilitation nursing process, application and outcomes. 3rd Ed. St Louis: Mosby Corporation; 2002.

3. Cusick J. Spirituality and voluntary pain. APS Bulletin 2003. Available from: http://www.ampainsoc.org/pub/bulletin/sep 03/path1.htm. Accessed on: 18 Aug 2005.

4. Golberg B. Connection: an exploration of spirituality in nursing care. JAN 1998;27: 836-42.

5. Unruch A. Spirituality, religion, and pain. Can J Nurs Res 2007;39:66-86.

6. Kelly F. Spiritualitiy and the celtic tiger period:change experienced by senior business leaders in the South East of Ireland. 2011. Available from: http://repository. wit.ie/1642/1/Spirituality_and_the_Celtic - T i g e r $\_$period ${ }_{-}-_{-}$c hanges experiences_by_senior_business_leaders_in_the_South_East_of_Ireland.pdf. Accessed on: 20 July 2012.

7. Eccleston C. Role of psychology in pain management. BJA 2001;87:144-52.

8. Crombez G, Vlaeyen JW, Heuts PH, Lysens R. Pain-related fear is more disabling than pain itself: evidence on the role of painrelated fear in chronic back pain disability. Pain 1999;80:329-39.

9. Means-Christensen AJ, Roy-Byrne PP, Sherbourne CD, et al. Relationships among pain, anxiety, and depression in primary care. Depress Anxiety 2008;25: 593-600.

10. Franck LS, Greenberg CS, Stevens B. Pain assessment in infants and children. Pediatr Clin North Am 2000;47:486-512.

11. Galloway KS, Yaster M. Pain and symptom control in terminally ill children. Pediatr Clin North Am 2000;47:711-46.

12. Wachholtz AB, Pearce MJ, Koenig $H$. Exploring the relationship between spirituality, coping, and pain. J Behav Med 2007;30:311-8.

13. Wachholtz AB, Pearce MJ. Shaking the blues away: energizing spiritual practices fort he treatment of chronic pain. In: Plante TG, ed. Contemplative practices in action. Spirituality,meditation, and health. Santa Barbara: Praeger; 2010.

14. Baetz ZM, Bowen R. Chronic pain and fatigue: associations with religion and spirituality. Pain Res Manag 2008;13:3838.

15. Snyder A. Complementary and alternative therapies. In: Monahan FD, Sands JK, Neighbors M, et al, eds. Phipps medicalsurgical nursing: health and illness perspectives. 8th Ed. St Louis: Mosby Elsevier; 2007.

16. Unruch A. Spirituality, religion, and pain. Can J Nurs Res 2007;39:66-86.

17. Koening HG. Chronic pain: biomedical and spiritual approaches. New York: The Haworth Pastoral Press; 2003.

18. Smith TB, McCullough ME, Poll J. Religiousness and depression: evidence for a main effect and the moderating influence of stressful life events. Psychol Bull 2003;129:614-36.

19. Whitford H, Oliver I, Peterson M. Spirituality as a core domain in the assessment of quality of life in oncology. Psycho-Oncol 2008;17:1121-8.

20. Newberg A, Pourdehnad M, Abass A, d'Aquili E. Cerebral blood flow during meditative prayer: preliminary findings and methodological issues. Percept Mot Skills 2003;97:625-30.

21. Ashby J, Lenhart R. Prayer as a coping strategy for chronic pain patients. Rehabil Psychol 1994;39:205-9.

22. Sheehan M. Spirituality and the care of people with life threatening illness. Tech Reg Anesth Pain Manag 2005;9:109-13.

23. 0'Connell-Edwards C, Edwards C, Pearce $\mathrm{M}$, et al. Religious coping and pain associated with sickle cell disease: exploration of a non-linear model. J Afr Am St 2009;13:113.

24. Mueller PS, Plevak DJ, Rummans TA. Religious involvement, spirituality, and medicine: Implications for clinical practice. Mayo Clin Proc 2001;76:1225-35.

25. Rippentrop E. A review of the role of religion and spirituality in chronic pain populations. Rehabil Psychol 2005;50:278-84.

26. Ano GG, Vasconcelles EB. Religious coping and psychological adjustment to stress: A meta-analysis. J Clin Psychol 2005;61:46180.

27. Bussing A, Michalsen A, Balzat H, et al. Are spirituality and religiosity resources for chronic pain conditions? Pain Med 2009;10:327-39.

28. Dezutter J, Luyckx K, Bussing A, Hutsebaut D. Exploring the link between religious attitudes and subjective wellbeing in chronic pain patients. Int $\mathrm{J}$ Psychiatr Med 2009;39:393-404.

29. d'Aquili E, Laughling C. The biopsychological determinates of religious ritual behavior. Zygon J Relig Sci 1975;10:32-58.

30. Affleck G, Urrows S, Tennen H, Higgins P. Appraisals of control and predictability in adapting to a chronic disease. J Pers Soc Psychol 1998;53:273-9.

31. Baldacchino D, Draper P. Spiritual coping strategies. A review of the nursing literature. JAN 2001;34:833-41.

32. Abbot NC, Harkness EF, Stevinson C, et al. Spiritual healing as a therapy for chronic pain: a randomized, clinical trial. Pain 2001;91:79-89.

33. Moreira-Almeida A, Koening HG. Religiousness and spirituality in fibromyalgia and chronic pain patients. Curr Pain Headache Rep 2008;12:327-32.

34. Wachholtz AB, Pearce MJ. Does spirituality as a coping mechanism help or hinder coping with chronic pain? Curr Pain Headache Rep 2009;13:127-32.

35. Rippentrop EA, Altmaier EM, Chen JJ, et al. The relationship between religion/spirituality and physical health, mental health, and pain in a chronic pain population. Pain 2005;116:311-21.

36. Keefe FJ, Affleck G, Lefebure J, et al. Living with rheumatoid arthritis: the role of daily spirituality and daily religious and spiritual coping. J Pain 2001;2:101-10.

37. Wachholtz AB, Keefe JF.What physicans should know about spirituality and chronic pain. South Med Assoc 2006;99:1174-5.

38. Glover-Graf N, Marini I, Buck J. Religious and spiritual beliefs and practices of persons with chronic pain. Rehabil Counsel Bull 2007;51:21-33.

39. Pargament KI, Smith BW, Koening HG, Perez C. Patterns of positive and negative religious coping with major life stressors. J Sci Study Religion 1998;37:710-24.

40. Bussing A, Michalsen A, Balzat HJ, et al. Are spirituality and religiosity resources for patients with chronic pain conditions? Pain Med 2009;10:327-39.

41. Bush E, Rye M, Brant C, et al. Religious coping with chronic pain. Appl Psychol Biofeedback 1999;24:249-60.

42. Wiech K, Farias M, Kahane G, et al. An fMRI study measuring analegesia enhanced by religion as a belief system. Pain 2009;139:467-76.

43. Dunn KS, Horgas AL. Religious and nonreligious coping in older adults experiencing chronic pain. Pain Manag Nurs 2004;5:19- 
28.

44. Wachholtz A, Pargament K. Is spirituality a critical ingredient of meditation? Comparing the effects of spiritual meditation, secular meditation, and relaxation on spiritual, psychological, cardiac, and pain outcomes. J Behav Med 2005;28:369-84.

45. Wachholtz A, Pargament A. Migranes and meditation: does spirituality matter? J Behav Med 2008;31:351-66.

46. Cumming JP, Pargament KI. Medicine for the spirit: religious coping in individuals with medical conditions. Religions 2010; 1:28-53.

47. Carteret M. Cultural aspects in pain management. 2010. Available from: http://www.dimensionsofculture.com/category/cultural-health-beliefs-behaviors/ page/2/.

48. Ozer S. Quality of life in patients with heart failure: ask the patients.
Heart\&Lung 2009;38:100-8.

49. Dedeli 0, Fadiloglu C, Uyer M. A survey cognitive behavioural model of pain in patient with chronic nonmalignan pain. MN-J Intern Med 2008;3:232-42. [Article in Turkish].

50. Afsar F, Pinar R. Kanser hastalarinda agri ve agri ile basetme yöntemlerinin de erlendirilmesi. Ataturk Universitesi Hemsirelik Yuksekokulu Dergisi 2003;6:19-28. [Article in Turkish].

51. Babaoglu E, Oz F. Terminal dönem kanser hastasina bakim veren eslerin duygusal ve sosyal sorunlari arasindaki ili ki. Hemsirelikte Arastirma Gelistirme Dergisi 2003;2:24-33. [Article in Turkish].

52. Karakavak G, Cirak Y. Kronik hastalikli cocugu olan annelerin yasadigi duygular. Egitim Fakultesi Dergisi 2006;7:95-112. [Article in Turkish].

53. Sulu E. Yogun bakimda yatan çocuk hasta- larin annelerinin manevi bakim (spirituel bakim) gereksinimleri. Doctoral Thesis Ege University Institute of Health Sciences. Izmir: Turkey; 2006.

54. Mardiyono MNS, Songwathana P, Petpichetchian W. Spirituality intervention and outcomes: corner stone of holistic practice. Nurse Media JNurs 2011;1:11727.

55. Howard V. A holistic approach to pain. Nurs Times 2001;97:34-5.

56. Thoresen CE. Spirituality and health: is there a relationship? J Health Psychol 1999;4:291-300.

57. Seeman TE, Dubin LF, Seeman M. Religiosity/spirituality and health. A critical review of the evidence for biological pathways. Am Psychol 2003;58:53-63.

58. Meador K. Spiritual care at the end of life. What is it and who does it? NC Med J 2004;65:226-8. 